\section{Ocean yearbook}

Ocean Yearbook 1. Edited by Elisabeth Mann Borgese and Norton Ginsburg. Pp. 890. (Pacem in Maribus/International Ocean Institute/University of Chicago Press: Chicago and London, 1979.) £17.50; \$25.

ElisABETH Mann Borgese, International Ocean Institute, Malta, and Norton Ginsburg, University of Chicago, are to be congratulated on getting their latest brainchild, the Ocean Yearbook, off the ground with its first edition, recently published. Although named a yearbook, the year in question has not been identified; however, the reports of the various organisations which appear in an Annex, cover 1976 and, in certain cases, to mid-1977.

Following a short Editors' Preface, Ocean Yearbook 1 contains a series of excellent topical articles on Issues and Prospects; Living Resources; Non-living Resources; Transportation and Communication; Marine Science and Technology; Environment; Coastal Management; Military Activities; and Regional Development. These are followed by a number of appendices covering reports from organisations, selected documents and proceedings, a directory of institutions, tables related to the articles, and an index.

The Yearbook is a long-awaited product of the International Ocean Institute, Malta, which is described in the Preface as "an offspring of an initiative of the Center for the Study of Democratic Institutions in Santa Barbara, California, USA". Publication of an Ocean Yearbook is the logical outcome of the present greatly increased interest in the Oceans which has been kindled by the Third United Nations Conference on the Law of the Sea. It is therefore vitally necessary to follow the developments which are taking place at the Conference, as presented in an excellent critique of the Informal Composite Negotiating Text (1977) by Arvid Pardo, who, in 1967, speaking as the Ambassador of Malta to the United Nations General Assembly, was originally responsible for drawing the attention of the world's governments to the potential of the oceans and their importance to the future of mankind.

Although the key to most other activities in the oceans, there is only one article on Marine Science (and Technology), Perspectives on the Sciences of the Sea by Lord Ritchie-Calder, who sounds a welljustified note of warning in his final two paragraphs. As stated by $\mathrm{Sir}$ Francis Beaufort, Hydrographer of the Navy (1829-1855), "The natural tendency of men is to undervalue what they cannot understand". The editors, by their ' $n$ balance of content in favour of applied activities at the expense of basic science, are giving credence to this unfortunate tendency which is particularly prevalent today in the United Nations system and amongst the national aid agencies.

I would also suggest that the selected Documents and Proceedings, contained in Appendix B, should be restricted to "a selection of international agreements, legislation and proceedings of international conferences" which have been finalised. Despite its relevance to Arvid Pardo's article, I query the desirability of reproducing in full the UNCLOS Informal Composite Negotiating Text which had already been replaced by a revised edition before the Yearbook was published.

The errors I have noted are minimal. This is a well compiled and well edited publication. My main fear is that the editors have set their sights too high and will be unable to maintain their

present standard and the sheer volume of information contained in the first edition; in any case, at yearly intervals as its name implies. I note only that in the bibliography to Lord Ritchie-Calder's article, Frye, P. is presumably Paul M. Fye, now President of the Corporation, Woods Hole Oceanographic Institution. I must also inform Tom Busha and James Dawson that the only flaw I can find in their most informative article on that excellent organisation IMCO is that the Hydrographic Department of the Admiralty was founded in 1795 (not 1759) when Alexander Dalrymple, Hydrographer to the East India Company, was appointed the first Hydrographer of the Navy.

Desmond P.D. Scott

\title{
Magnetohydrodynamic stability
}

MHD Instabilities. By G. Bateman. Pp. 263. (MIT Press: Cambridge, Massachusetts, and London, 1979.) $£ 15.75 ; \$ 22.50$.

DESPITE the generality of its title this book addresses rather specifically the question of magnetohydrodynamic stability as it relates to the currently most promising approach to magnetic confinement of fusion plasmas, the Tokamak. This is perhaps surprising in a book the content of which is primarily didactic. However, the result is a relatively compact book which maintains coherence and covers much ground that is of fundamental importance to the subject.

Dr Bateman begins from a virtually axiomatic statement of the governing MHD equations, moderated by a brief enumeration of effects neglected by the MHD formulation. He then proceeds by way of an illustrative chapter on the Rayleigh-Taylor Instability to a development of the theory of equilibrium and linear stability and a derivation of the energy principle. Cylindrical and toroidal geometries are treated and then high beta questions. Non-linear evolution and resistive instabilities each have a chapter. All this theory is sandwiched between two experimental chapters: the first serving as an introduction and motivation, the last as a comparison between theory and experiment.

Although the mathematical details are included in several cases, the emphasis throughout is on understanding the physical concepts. It is refreshing to read so clear an exposition of the physics in a subject which is so often obscured by a tangle of algebra or mystified by the ubiquitous computer 'simulation'. Not that these are absent, but they are treated with a light, often qualitative, touch, drawing frequently on references to the literature. This approach may feel unsatisfactory for some and it disqualifies the book from being a true reference volume or probably even a self-contained text. However, it greatly enhances its value as an introduction to the subject, and the references (many commendably recent) are there for those who want something heavier to chew on. The provocative questions scattered through the text are great fun.

A serious attempt is made to relate the theory to the experimental context but the connection is not always made really clear. This reflects partly the state of the subject but also an inherent ambivalance in the book between a presentation of fundamentals and a review of current Tokamak MHD research. Given that problem, it seems a pity that Dr Bateman did not choose a rather broader spectrum of applications, to include at least other related toroidal plasma confinement schemes, such as the reversed field pinch in which MHD instabilities are of at least as great importance as in Tokamaks.

MHD Instabilities serves as an excellent introduction for students and researchers in magnetic confinement MHD theory. Its treatment of Tokamak-related problems should prove of great value to the growing numbers in Tokamak research, many of whom are not directly involved in MHD research as such but for whom MHD stability is vital in determining the plasma environment.

I.H. Hutchinson

I.H. Hutchinson is Principal Research Scientist at the Plasma Fusion Center/Frances Bitter National Magnet Laboratory, Massachusetts Institute of Technology, Cambridge, Massachusetts. 